\section{OPEN ACCESS}

Volume: 7

Issue: 2

Month: October

Year: 2019

P-ISSN: 2321-4643

E-ISSN: 2581-9402

Received: 21.08.2019

Accepted: 30.09 .2019

Published: 03.10.2019

Citation:

Kumar, KR, and BN

Sivakumar. "An Assessment of Assuring E-Learning Education Quality on MBA Program in Tamil Nadu, India.” Shanlax International Journal of Management, vol. 7, no. 2, 2019, pp. 37-46.

DOI:

https://doi.org/10.34293/ management.v7i2.651

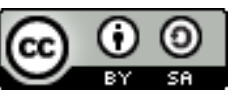

This work is licensed under a Creative Commons Attribution-ShareAlike 4.0 International License.

\title{
An Assessment of Assuring E-Learning Education Quality on MBA Program in Tamil Nadu, India
}

\section{K.R.Kumar}

Associate Professor, Department of MBA

Adhiyamaan College of Engineering (Autonomous), Hosur, Tamil Nadu, India

\section{B.N.Sivakumar}

Director, Department of MBA

Adhiyamaan College of Engineering (Autonomous), Hosur, Tamil Nadu, India

\begin{abstract}
As of late, numerous colleges and instructive organizations have made extensive interests in e-learning frameworks. These are frameworks that convey instructive administrations by means of electronic channels. Administration quality has been examined in past research as a basic factor for estimating frameworks achievement. Unassuming consideration has been paid to factors influencing the administration conveyance quality in the e-learning field. The goal of this examination is to recognize the factors considered to affect the e-learning frameworks benefit conveyance quality through a review of partners. The principle finding of this investigation is that IT foundation, framework quality, and data quality altogether influence benefit conveyance quality in the e-learning frameworks field. IT framework administrations were found to assume a basic part in enhancing framework quality and data quality, and this develop can be considered as an establishment of conveying top notch instructive administrations.

Keywords: Bench marking, Continuous improvement, Carrier advancement and Information, E-learning, Tamilnadu
\end{abstract}

\section{Introduction}

With the improvement of innovation, India has seen an upgraded acknowledgment of online training over a time of couple of years. Numerous understudies and working experts have joined distinctive e-learning stages in the previous couple of years to improve their abilities. Furthermore, taking a gander at patterns, the quantity of individuals receiving on the web training stages is relied upon to increment essentially sooner rather than later. According to an ongoing report discharged by KPMG India and Google, Online Education in India: 2021, the market for online instruction in India is required to observe a wonderful development of eight times in the following five years, i.e., from USD 247 million of every 2016 to USD 1.96 billion out of 2021. Such high development in online instruction showcase is anticipated to be the result of expanded number of paid online training clients from 1.57 million of every 2016 to 9.5 million out of 2021. Thus, as the market for e-learning is anticipated to develop numerous occasions in the coming years, let us see some rising patterns in Indian online advanced education framework.

\section{Rising Trends in Indian Online Higher Education System \\ India has one of the biggest advanced education frameworks on the planet. It fundamentally comprises of three Sections College, school, and course.}


What's more, all parts of the advanced education framework are represented by the University Grants Commission and its expert boards. As indicated by KPMG report, online advanced education in India is at a beginning period of improvement and has seen rise of various private colleges offering UG and PG e-learning courses to understudies. In any case, when contrasted with graduation and confirmation courses, the interest for online advanced education is ruled by post-graduation courses, for example, MBA and MCA. Manners by which online instruction enables contender to plan effectively for various focused exams are as per the following:

\section{Webinar}

A class directed in the online mode is alluded to as an online class. Nowadays numerous online players direct online courses that assistance competitors in reasonable lucidity.

\section{Mock Tests}

Mock tests are developing as a well known course segment for understudies wherein they take an interest in a progression of tests and get a near appraisal (with different understudies) of their execution. With taunt tests, applicants likewise become more acquainted with their zones of change and additionally test example of the focused exam they want to show up for.

\section{Videos}

Videos are useful for competitors in taking care of exam papers and other issue regions.

\section{Counseling}

As a differentiator, players in online test prep showcase have likewise begun offering course and vocation directing administrations to understudies.

\section{Online Education: Why it is Gaining Popularity}

According to KPMG report, there are numerous reasons why understudies and working experts are moving towards e-learning/online training. Examine some such reasons underneath.

\section{Internet Infiltration}

India has a web entrance of around 31\% today, which implies 409 million web clients. It is anticipated that by 2021, there will be about 735 million web clients in India, which will prompt increment in rush hour gridlock for online training players.

\section{Smartphone Entrance}

Currently, there are 290 million cell phone clients in India and the client base is required to develop with the expansion of another 180 million new clients by 2021.

\section{Flexibility of Time}

This is particularly valid for working experts who have time imperatives in seeking after a disconnected course. Seeking after a course in online mode enables a man to perform various tasks with other work and family duties.

\section{Quality Instruction}

There are regions in India where there is absence of value disconnected training. For example, states such Bihar, Kerala and in addition Jammu and Kashmir represent around four lakh remove training enlistments, states KPMG report.

\section{Immediate Outcomes}

Online training enables contender to get quick outcomes for any test that they show up for. This further encourages them in getting ready for exams all the more proficiently.

\section{Government Activities}

Government's ongoing activities, for example, SWAYAM, e-Basta, and Digital India is relied upon to fortify the foundation required by understudies to seek after training in online mode.

\section{Study Material}

An assortment of online examination material as recordings and writings are urging understudies to receive online training stages.

\section{Affordability}

Online courses joined at UG or PG level are substantially more reasonable than conventional projects as portrayed in the picture beneath. 
In India, each organization offering MBA courses independently decides the affirmation procedure with no unmistakable standard of assessment. The obsolete educational programs, as well, is a key factor for decrease in work offers. Because of the financial advancement in the year 1991, the private division unshackled which prompted an expanded interest for MBAs. Organizations were eager to pay the as much as possible to this new type of officials who were viewed as ponder kids fit for putting family-held, conventional organizations on quick track. Henceforth, MBA turned into a win mantra and administration turned into the most looked for offer profession for graduates. MBA symbolized status and cash. Indeed, even the individuals who figured out how to get into B-or C-review business colleges could rest guaranteed that they had made it throughout everyday life. Shockingly today, the degree is continuously losing its notoriety. According to investigate, around 2, 00,000 understudies moved on from 5,000 administration foundations in the year 2016-17. While the best establishments still hold some legitimacy in the business, the others are not really ready to gloat of value administration training that can enable their graduates to anchor work and just $7 \%$ end up being employable, says an examination directed by ASSOCHAM. In 2016-17, the greater part of MBA graduates couldn't get enlisted amid grounds situations. Information by All India Council for Technical Education (AICTE) demonstrates only $47 \%$ of MBAs were set, $4 \%$ not as much as the earlier year, and at a five-year low. Information proposes that in excess of $220 \mathrm{~B}$-schools in top urban communities in India have closed down as an immediate aftereffect of a $45 \%$ lessening in grounds enlistment. Around 120 more B-schools are slated to meet a similar destiny, this year. A portion of the explanations behind the decay of the once looked for after projects in India have been examined and all around archived. Notwithstanding, what most examination passes up a great opportunity for is a standard of assessment and estimating the benefits of an understudy instead of an Institute. Dissimilar to the West which has a uniform determination procedure of GMAT, where clear positioning and legitimacy decides the Institute to which the understudy is chosen. In India, we have each foundation self-governing deciding the confirmation procedure with no unmistakable standard of assessment. Additionally, the capability gave out by the different foundations ranges from a degree to a certificate, from a full-time to an online program, all guaranteeing to be a substantial MBA degree without a quantifiable scale for the business with which to assess. Numerous businesses throughout the years have learnt the most difficult way possible that any degree-holding individual wouldn't take the organization higher than ever. The majority of these organizations are driven by business objectives as opposed to instructive objectives and consequently e-learning quality and foundation are endangered as opposed to the charges.

Not with standing, the obsolete educational programs is the principle explanation behind the decrease in the activity offers to MBA degree holders in India. This has been expressed previously and training bodies like AICTE are dealing with the hole amongst scholastics and industry. The administration educational modules has not been inspected by schools and colleges according to changing corporate segment B-schools are yet to see the shrewdness in dovetailing their educational modules to the changing business prerequisites and new difficulties looked by the organizations today.

Establishments today likewise trade off on the nature of the personnel essentially because of the inaccessibility of good able workforce and the cost of obtaining such employees. In a perfect world, the personnel of a MBA school must be business visionaries and industry pioneers with the goal that the understudies get the opportunity to gain from their experience. Excepting top Institutes like IIMs, such sessions are infrequently led in the universities. Indian foundations and colleges ought to gain from and receive best practices from a portion of the best remote colleges to beat these difficulties.

One will never know about low e-learning quality graduates leaving schools like Kellogs or Wharton's since they demand work understanding. It's anything but a section level degree there. The pattern in India of getting a MBA first and after that landing a position is evolving. The midyear entry level position is typically used to connect this hole in India. India's employability emergency is all the 
more genuine in light of the fact that the larger part of its populace is youthful. Jobless youth is one of the greatest difficulties that our nation faces. Private venture is down and subsequently work creation is moderate.

$\mathrm{Be}$ that as it may, the silver fixing is enterprise with more new companies on both the net and block and concrete. What's more, MBAs are better situated for these new organizations. Here are a few recommendations for Universities offering MBA degrees to support fantastic graduates:

- Build a decent staff and pay them well

- Get a blend of doctorates and industrialists as instructors

- All administration foundations can't deliver understudies to fit into employments of MNCs, and vast SMEs are similarly imperative

- Train and manufacture business enterprise and

- Understand India and corporate needs, and tailor instruction in like manner

\section{Review of Literature}

Anna Saiti, (2012) this paper intends to look at whether educational activity in Greece executes the estimations of total e-learning quality organization and adds to the difference in the informational technique, and to offer suggestions for a structure of total e-learning quality organization that would add to an adjustment in the general idea of the preparation methodology. The paper relies upon speculative examination and on the current definitive framework. Three one of a kind parts of the Greek preparing structure are on a very basic level investigated and discussed. This examination sees that, due basically to the nonattendance of a longterm informative procedure, the nonappearance of an educational expert change program and compelled budgetary help, the Greek informational structure needs to review its structure and frameworkseven those that are "thought little of". Given the differentiations among preparing and industry, and the manner in which that solitary three special parts of the Greek direction structure are investigated here, more research and examination would be required in this field. The paper is profitable to educational coordinators and game plan makers. From the perspective of total e-learning quality organization, there may be a noteworthy impact on the change parts and yields in preparing, adding to a country's social and fiscal well-being. Cláudia S. Sarrico and Maria J. Rosa, (2016) the inspiration driving this paper is to present and discuss the possibility of generation arrange e-learning quality organization (SCQM) in direction. The correct work relies upon a country logical investigation which joins data on four propelled instruction associations and nine assistant schools. Data are procured from national and institutional records, and likewise from individual and board interviews. The makers have used substance examination for the two data and meeting transcripts. The makers find that however we can consider direction structures as supply chains, there are indispensable troubles to SCQM in preparing, particularly, as for information sharing, trust, compromise and organization. Then again, the makers have found some improvised extraordinary practice which could be created into more proficient SCQM sharpen. The work could light up course of action makers and what's more institutional pioneers on sharpens that would improve the execution of the preparation creation arrange. Guideline is a basic development division with a strong impact on the flourishing of social requests. Gets in preparing execution coming to fruition as a result of better SCQM in guideline would in this way influence every one of us.

Erwin Rausch, (2007) the paper suggests that highlight on criteria (rules) for e-learning quality decisions would contribute basically to making activity topics in organization guideline and change more utilitarian. It offers a theoretical model involving rules as six requests. The model could fill in as foundation for investigate and the change of various models that may better suit the different needs of pioneers in different conditions. The article raises that the model is sweeping and emphatically in perspective of the written work. A circumstance is analyzed with the use of the model to exhibit its useful application and points of interest. The model is wanted to give sensible use and usage of specialist and motivation theories in organization and private life. G. Srikanthan and John Dalrymple, (2004) the paper tries to amalgamation the features of the model for e-learning quality organization in 
preparing in perspective of the techniques spelt out in four well-articulated methodologies for the demonstration of significant worth in cutting edge instruction. Each framework adds to different points of view of preparing from the understudies' and the foundation's perspectives, offering segments to the model. The push of the model is a "transformative" approach to manage accomplishes a focal change in understudies' understanding. In the finish of the makers the four philosophies advance themselves to be synergistically joined to shape the parts of the model, which sets up the purpose behind e-learning quality in preparing in schools.

John Cullen et al, (2003) thoughts of mindful organization in the overall public division have ensured that issues relating to execution estimation have been high on the inspiration of cutting edge instruction establishments. A couple of value exercises are going ahead meanwhile as universities are looked with diminishing cash related assistance from open wellsprings of reserve. It has been recommended that best in class training should look to private part models of execution estimation with a particular true objective to address basic e-learning quality issues. In taking such models, the paper fights the noteworthiness of seeing that key execution pointers isolated can be broken aside from on the off chance that they are grounded inside the lifestyle of a strategy-focussed affiliation. The paper by then proposes the usage of a balanced scorecard approach remembering the true objective to fortify the hugeness of administering instead of basically checking execution. Kim O'Mahony and Thomas N. Garavan, (2012) this paper intends to report and explore the activities picked up from a relevant examination on the execution of an e-learning quality organization system inside an IT Division in a propelled training (HE) affiliation. The paper relies upon a review of the imperative compositions and the usage of basic sources, for instance, record examination, part discernment and gatherings to develop a logical examination that depicts and evaluates the execution method. The logical examination perceives four components key to the convincing utilization of the e-learning quality organization system inside a Division of a HE establishment: senior activity and sponsorship; accomplice duty; the organization of culture change; and completing e-learning quality techniques. The relevant examination reveals that the execution of significant worth organization structures requires oversaw effort, steady expert, and the whole deal duty of benefits and exact assessing of execution and is best done on an incremental introduce. The paper relies upon a singular affiliation logical examination and utilizations a combination of data amassing systems to make disclosures. The examination revelations speak to those HE foundations may gain more important ground in executing e-learning quality organization structures if they focus on a particular division instead of an organisation-wide approach.

R. Jagadeesh, (2000) the growing enthusiasm for postgraduate preparing in organization in India has realized an unstable rising in the amount of associations offering such guideline. In any case, the nature of direction offered in various foundations is genuinely being exchanged words by understudies and up and coming organizations. The undertakings to upgrade e-learning quality appear to be irrelevant, achieving beside zero change in e-learning quality. Further, the paper delineates the structure and case of post-graduate organization guideline as offered in India, close by a depiction of managerial associations existing in the country to screen the benchmarks of organization preparing. Towards the end, prescribes fitting game plans with a couple of decisions, to upgrade e-learning quality, discussing moreover their credibility. The general objective is to offer help to make procedures to improving nature of postgraduate guideline in organization.

Ritika Mahajan et al, (2014) reason and estimation of organization direction were continually under the analysts' scanner yet the duplication of associations instigated a real affable contention on its e-learning quality. The purpose behind this paper is to perceive the factors affecting nature of organization guideline in India and clears up their demeanor, centrality and shared effects using interpretive fundamental illustrating (ISM). Leadership created as the most indispensable factor took after by definitive structure and practices. Interrelations by and large not successfully perceivable set up their detectable e-learning quality. Ritu Narang (2012) Keeping as a best need the basic need to pass on e-learning quality 
direction in cutting edge training establishments, the present paper attempts to check the e-learning quality perspective of organization understudies in India. In perspective of an exploratory examination a balanced variation of SERVQUAL was used as the examination instrument. Data were accumulated from energetic understudies between the ages of 2125 years. The examination instrument, EduQUAL, containing 28 things attempted well for both steady e-learning quality and authenticity. Five estimations of the scale, to be particular learning results, responsiveness, physical workplaces, character change and scholastics were recognized. The results got pointed at the negative e-learning quality openings in all the five estimations of EduQUAL. The most lifted negative gap was unquestionable in the physical workplaces estimation and slightest negative score if there ought to be an event of scholastics estimation. There were basic differences among acknowledgments and wants for understudies concerning all the five estimations of the scale $(p<0.001)$. The examination was confined to three open informational associations so the theories for the entire nation must be used vigilantly. Thusly, the experts are asked to extend this investigation to private and remote universities moreover. The present examination gives critical bits of learning into the idea of cutting edge training saw by understudies in India.

Sangeeta Sahney et al, (2004) keeping with the socio-economic and social change that has set more exceptional demands on the informative system, to the extent more unmistakable obligation and duty and extended wants by accomplices, the structure has been pressurized to move its fixation from one in quantitative improvement to one with highlight on e-learning quality. Such moves and changes are being found in the made countries, and in the making countries of the world. The direction system, and simply more so the propelled instruction structure particularly, endeavoring to react to the solicitations and reliably growing weights from its accomplices, winds up in a market-oriented circumstance, with inward and external customers; wherein, "satisfying the customer", is the supervisor for survival as time goes on. "Satisfying the customer", is the middle message of total e-learning quality organization
(TQM) and, in this way, there is a need to perceive and apply the pertinent thoughts of TQM to each and every piece of insightful life; that is, to the instructing, learning and legitimate activities. The paper is a theoretical undertaking at conceptualizing TQM in preparing.

Sanjeev Verma and Ram Komal Prasad, (2017) the inspiration driving this paper is to develop a precisely endorsed scale to measure the understudies' impression of organization e-learning quality in organization direction. In this examination, a three-mastermind deliberate arrangement of scale change has been grasped. At first, surviving written work overview depicted the create. Exploratory examination strategies like focus pack study and ace end helped in refining the scale. In the second stage, fundamental part examination with varimax rotate and Kaiser Normalization (exploratory factor examination) was used to refine the scale. Finally, multi-property multimethod grid examination was done to test the immovable e-learning quality and authenticity of the scale. A 25-thing multidimensional create with six components (academic perspective, capable affirmation, direct responses and sponsorships, industry association correspondence, non-educational points and physical help) was gathered legitimately to quantify advantage e-learning quality in organization guideline. Psychometrically, the scale indicates internal consistency and remains unfaltering over the cases. Consistent and composed multi-dimensional produce for advantage e-learning quality in organization guideline will energize academicians, executives and controllers in illustrating a method masterminded structure for enhanced understudy satisfaction and execution. This examination is an incremental undertaking to develop a precisely endorsed scale for evaluating the organization e-learning quality level and resultant satisfaction in organization preparing.

Sylvia Chong, (2014) E-learning quality attestation and organization is essential for the steady difference in the substance, movement and headway of teacher preparing programs. This paper hopes to research speculative issues and contemplations in looking over the e-learning quality plan of instructors in the Singapore setting. An academic e-learning quality framework gives a 
building approach to manage streamlining e-learning quality strategies, advancing from a detached course of action of significant worth methods to an organized work process in perspective of set up best practices. The plan structure gave a ponder focus to make and bolster the academic idea of the teacher progression programs. E-learning quality change and headways occur through facilitated exertion and learning. The highlight is on e-learning quality organization as a strategy arranged system. There is a move in perspective from standard models of program evaluation to a systems approach that fuses multi-dimensional models to influence association, teaching and ask about in an educator preparing foundation. Subsequently Singapore's teacher preparing e-learning quality organization should be considered past a course of action of estimation gadgets towards an orderly, arranged and focused examination with everything taken into account, as a method arranged strategy.

\section{Research Problems}

A survey the writing of data frameworks and e-learning frameworks demonstrates that the dominant part of concentrates to date considered SDQ as an exogenous factor that affects the achievement pointers. The factors influencing administration conveyance quality, specifically in the e-learning framework field have gotten sparse consideration. The issue of SDQ is thought to be more confused in e-learning frameworks on the grounds that the relationship between the administrations supplier and beneficiary is sorted out through an electronic channel, and that may prompt troubles in enough understanding the clients' needs.

\section{Research Objectives}

1. To realize the average of e-learning quality of management education in Tamilnadu

2. To review of relation between e-learning quality of management education and Overall faculty delightful in E-learning quality System

\section{Research Hypothesis}

$\mathbf{H}_{01}$ : There is no positive relationship between bench marking Vs Overall faculty delightful in E-learning quality System

$\mathbf{H}_{\mathbf{0} 2}$ : There is no positive relationship between Feedback and Continuous Improvement Vs Overall faculty delightful in E-learning quality System

$\mathbf{H}_{03}$ : There is no positive relationship between Institution and process Vs Overall faculty delightful in E-learning quality System

$\mathbf{H}_{04}$ : There is no positive relationship between Carrier advancement Vs Overall faculties delightful in E-learning quality System

$\mathbf{H}_{\mathbf{0 5}}$ : There is no positive relationship between Information and credentials Vs Overall faculty delightful in E-learning quality System

\section{Methodology}

- Research Design: Descriptive

- Scaling: Likert

- Sampling: Purposive

- Data from: Primary and Secondary data collection

- Data collection Tool: Questionnaire methods

\section{Results Analysis}

Table 1 Demographic Breakdown

\begin{tabular}{|l|c|c|}
\hline & Frequency & \% \\
\hline Gender \\
\hline Male & 95 & 67.85 \\
\hline Female & 45 & 32.14 \\
\hline Age \\
\hline$<=20$ & 25 & 17.85 \\
\hline 21 to 30 & 60 & 42.85 \\
\hline$>31$ & 55 & 39.28 \\
\hline Education & 110 & 78.57 \\
\hline PG & 30 & 21.42 \\
\hline$>$ PG & 55 & 39.28 \\
\hline Income per year in Lakh \\
\hline$<=5$ & 47 & 33.57 \\
\hline 5.1 to 8 & 38 & 27.14 \\
\hline$>8.1$ & \multicolumn{3}{|l}{} \\
\hline \multicolumn{4}{|l|}{} \\
\hline
\end{tabular}


International Journal of Management

Table 2 Descriptive Analysis of E-Learning Quality of Management Education

\begin{tabular}{|c|c|c|c|c|c|}
\hline & Mean & SD & $\begin{array}{l}\text { Factors } \\
\text { Loading }\end{array}$ & $\begin{array}{c}\text { Cronbach } \\
\text { Alpha }\end{array}$ & KMO \\
\hline Bench marking & & & 0.873 & & \\
\hline Accreditation like NBA, NAAC and etc., & 0.34 & 1.09 & 0.850 & \multirow{3}{*}{0.755} & \multirow{3}{*}{0.810} \\
\hline Domestic and International Ranking & 0.38 & 0.99 & 0.742 & & \\
\hline Responsibility of Management Education & 0.41 & 0.91 & 0.711 & & \\
\hline \multicolumn{6}{|l|}{ Feedback and Continuous Improvement } \\
\hline Assurance of learning & 0.39 & 1.08 & 0.773 & \multirow{7}{*}{0.814} & \multirow{7}{*}{0.895} \\
\hline Appropriate Academic reports & 0.38 & 0.38 & 0.761 & & \\
\hline Key performances indicators & 0.41 & 1.05 & 0.755 & & \\
\hline Students, alumni and employers survey & 0.42 & 0.99 & 0.744 & & \\
\hline Course progression & 0.35 & 0.96 & 0.739 & & \\
\hline Self, Peer and superior evolution reports & 0.36 & 0.97 & 0.722 & & \\
\hline National wise academic audit & 0.35 & 0.95 & 0.719 & & \\
\hline \multicolumn{6}{|l|}{ Institution and process } \\
\hline Decision making charts & 0.31 & 1.08 & 0.814 & \multirow{4}{*}{0.716} & \multirow{4}{*}{0.811} \\
\hline Academic E-learning quality councils & 0.33 & 1.07 & 0.732 & & \\
\hline Pedagogical enhancement & 0.39 & 1.05 & 0.712 & & \\
\hline Accountability and reasonability of individual & 0.35 & 0.99 & 0.709 & & \\
\hline \multicolumn{6}{|l|}{ Carrier advancement } \\
\hline Incentive system & 0.39 & 0.99 & 0.664 & \multirow{4}{*}{0.931} & \multirow{4}{*}{0.754} \\
\hline Configuration of KPIs in teaching and research & 0.38 & 0.97 & 0.612 & & \\
\hline Faculty development program & 0.41 & 0.89 & 0.604 & & \\
\hline Leadership tanning & 0.42 & 0.84 & 0.601 & & \\
\hline \multicolumn{6}{|l|}{ Information and credentials } \\
\hline Information management system & 0.35 & 1.08 & 0.589 & \multirow{4}{*}{0.688} & \multirow{4}{*}{0.782} \\
\hline E-learning quality manual liked to documentations & 0.36 & 1.07 & 0.577 & & \\
\hline Kick-off new ideas & 0.32 & 1.05 & 0.568 & & \\
\hline Faculty and staff meeting & 0.39 & 0.99 & 0.554 & & \\
\hline
\end{tabular}

\section{Figure 1 Correlation analysis Independent} variables Vs Dependent variables

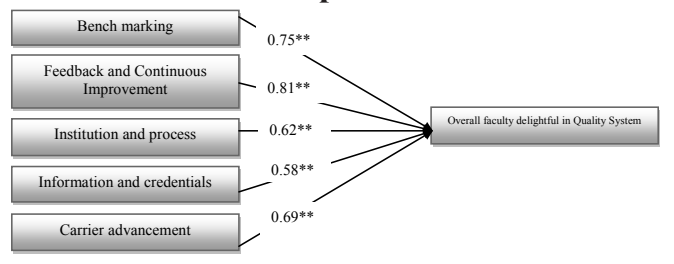

\section{Conclusion and Future Research Scope}

Accessibility, understandability, and brevity were fundamental angle to quantify data nature of e-learning frameworks. These angles are considered to be critical for understudies to accomplish the required instructive undertakings through electronic channels. For example, understudies need to get some data toward the begin obviously with respect to the subjects in this course, course pioneer/ analyst, task due dates, examinations, appraisal subtle elements, and content and materials required in the course. This data ought to be accessible to understudies in a succinct and reasonable frame. Amid conveyance of the course, the viewpoints above ought to be considered in the course materials gave to understudies. These perspectives can add to maintain the nature of instructive administrations and course materials conveyed to understudies, and 
make positive affections for understudies towards the e-learning frameworks. Data quality affected five of the six sub-measurements of Service delivery quality. The parts of data quality, accessibility, understandability and brevity assume a basic part in furnishing understudies with high caliber instructive administrations. The effectiveness of administrations is related with the capacity of understudies to clarify and comprehend the substance of materials. Understudies can't get the course materials, criticism, or associate with other partners without framework accessibility.

The move towards global knowledge economies has resulted in governments around the world responding to the emergent global education agenda through education reforms designed to meet their national economic and social goals. These goals become embedded in legislation and steer the policy direction of higher education. The concern for e-learning quality has emerged as part of these reforms and challenges both the traditional academic notion of collegial e-learning quality assurance and that of the managerial approach adopted by e-learning quality bodies. The emphasis of e-learning quality bodies' external audits in Tamil Nadu was not so much on institutions demonstrating good teaching and learning (some would say at the heart of education) as it was on institutions having e-learning quality control of the systems to support teaching and learning.

Power shifted from the people in the institutions to a system of indirect government control through e-learning quality bodies using monitoring evaluation to check that institutions were on track for meeting desired outcomes. Intuitions supervisor from the study supported the notion that e-learning quality is best assured by institutions having direct sense of ownership of their e-learning quality procedures both at individual and institutional levels. For management education sector to compete successfully in the global knowledge economy it must have in place e-learning quality systems that emphasize transparency, accountability and comparability with other e-learning quality systems internationally. A dilemma faces the Tamil Nadu Government with regard to e-learning quality assurance of the tertiary sector, that is, to find a suitable balance between the policy goal of assuring the e-learning quality of the education it funds, and the administrative aim of ensuring that institutions have greater control over their own goals, operations, and associated e-learning quality assurance activities. In conclusion, e-learning quality is an enigmatic notion, challenging the interpretations and implementation strategies of government e-learning quality agencies and institutions.

There were certain limitations that we encountered during the development process. A major limitation in the survey was that only respondents involved in management education were examined and data were obtained from only few districts in Tamil Nadu MBA program. Additionally, comparisons could be made between on-campus MBA faculties. Research could also examine how potential MBA faculties determine e-learning quality as this will help in developing and MBA programs. Finally, researching information on the perceived differences between on campus MBA programs would be helpful for future research. Thus, this study hopes to encourage further discussion and analysis on the critical factors in online MBA education.

Taking a gander at the present patterns, it is normal that online advanced education market will observe significant development in the following five years and help in remove learning programs. In any case, since these courses are constrained to hypothetical substance at present, selection of virtual classroom ideas could get a reasonable segment the online medium.

Aside from that, more number of understudies, particularly from level 2 and 3 urban communities are relied upon to embrace diverse online channels to plan for focused exams. This is thinking about the constrained choices accessible for disconnected test arrangement at these spots. Half and half model is required to pick up footing in future, where online players are relied upon to open disconnected focuses to give classroom-like understanding to understudies. Additionally, gamification, the approach of presenting fun components like computer game outline in learning, is probably going to pick up prevalence in India. According to the report, a few players have just begun entering the space so as to improve commitment of students. 


\section{References}

Chong, S. "Academic E-Learning Quality Management in Teacher Education: A Singapore Perspective." E-learning quality Assurance in Education, vol. 22, no. 1, 2014, pp. 53-64.

Cullen, J, Joyce, J, Hassall, T and Broadbent, M. "E-Learning Quality in Higher Education: From Monitoring to Management." E-Learning Quality Assurance in Education, vol. 11, no. 1, 2003, pp. 5-14.

Jagadeesh, R. "Assuring E-Learning Quality in Management Education: The Indian Context." E-Learning Quality Assurance in Education, vol. 8, no. 3, 2000, pp. 110-119.

Mahajan, R, Agrawal, R, Sharma, V and Nangia, V. "Factors Affecting E-Learning Quality of Management Education in India: An Interpretive Structural Modelling Approach.” International Journal of Educational Management, vol. 28, no. 4, 2014, pp. 379-399.

Narang, R. "How do Management Students Perceive the E-Learning Quality of Education in Public Institutions?." E-learning Quality Assurance in Education, vol. 20, no. 4, 2012, pp. 357-371.

O'Mahony, K, Garavan, TN. "Implementing a E-Learning Quality Management Framework in a Higher Education Organisation: A Case Study." E-learning Quality Assurance in Education, vol. 20, no. 2, 2012, pp. 184-200.
Rausch, E. "Leadership in Management Education and Development: Criteria for E-Learning Quality Decisions." European Business Review, vol. 19, no. 3, 2007, pp. 257-268.

Sahney, S, Banwet, DK and Karunes, S. "Conceptualizing Total E-Learning Quality Management in Higher Education." The TQM Magazine, vol. 16, no. 2, 2004, pp.145-159.

Saiti, A. "Leadership and E-Learning Quality Management: An Analysis of Three Key Features of the Greek Education System.” E-Learning Quality Assurance in Education, vol. 20, no. 2, 2012, pp. 110-138.

Sarrico, CS and Rosa, MJ. "Supply Chain E-Learning Quality Management in Education." International Journal of E-Learning Quality \& Reliability Management, vol. 33, no. 4, 2016, pp. 499-517.

Srikanthan, G and Dalrymple, J. "A Synthesis of a E-Learning Quality Management Model for Education in Universities." International Journal of Educational Management, vol. 18, no. 4, 2004, pp. 266-279.

Verma, S and Komal Prasad, R. "The MEQUAL Scale: Measure of Service E-Learning Quality in Management Education." International Journal of Comparative Education and Development, vol. 19, no. 4, 2017, pp. 193-206.

\section{Author Details}

Dr.K.R.Kumar, Associate Professor, Department of MBA, Adhiyamaan College of Engineering (Autonomous), Hosur,Tamil Nadu, India,Email ID: krkquality@gmail.com

Dr.B.N.Sivakumar, Director, Department of MBA, Adhiyamaan College of Engineering (Autonomous), Hosur, Tamil Nadu, India. 